Annals of Plant Sciences

ISSN: 2287-688X

OPEN ACCESS

Research Article

www.annalsofplantsciences.com

\title{
Traditional Health Care (THC) and nutritional practices in Mother Child Health Care systems (MCHCs) in the tribal dominated areas of Rajasthan, India.
}

G.S. Deora ${ }^{1 *}$ and M.S. Rathore ${ }^{2}$

${ }^{1}$ Center of Advanced Study, Department of Botany, Faculty of Science, Jai Narain Vyas University, Jodhpur (Rajasthan) 342005- India.

${ }^{2}$ Department of Botany, Faculty of Science, Bhupal Nobles' University Udaipur, (Rajasthan) - 313001-India

Received: 1/13/2018; Revised: 1/19/2018; Accepted: 1/27/2018

\begin{abstract}
Plants and plants based products are frequently used by the tribals for their health and treatment right from human civilization. The present study was conducted in the tribal dominated areas of Rajasthan such as Banswara, Chittorgarh, Dungarpur, Pratapgarh and Udaipur which are mainly dominated by the Bhil, Meena, Garasia and Kathodia tribes. During study informations were collected from the Dais or Gunis, tribal health practitioners. In the present work 55 plant species belonging to 52 genera and 35 families have collected, identified and documented which are used to treat different types of mother child ailments after the birth and up to five years age of child. Similarly, informations were also documented about the plants their parts which were used for nutritional purposes during the lactation period of mother and for the amelioration of the health of mother and child.
\end{abstract}

Keywords: Traditional health care, Nutritional practices, Mother-child, Tribals, Dais, Amelioration

\section{Introduction}

Plants and plants based products are frequently used by the tribals for their health and treatment right from early human civilization. In the ancient time women developed skills to look after the health of their families and surrounding communities through traditional system of treatment. They were able to treat or control the common diseases among their children and themselves. Women always functioned as the carrier of such type of health traditions which passed through generation to generation. The knowledge of traditional women health practitioners such as Nawan/Nayan or traditional Bais, Dais, midwives (also known as traditional birth attendants) has become confined to their communities and families. The practices and attitude towards traditional medicine and role of women health practitioners has undergone a series of change. With the development of modern science and medicine their traditional practices of nutrition and health are vanishing very fast. With the introduction of modern system of health and medicine and reducing recognition of traditional health practices of mother- child health care, this knowledge is rapidly disappearing. Therefore, it is necessary to document such important traditional health care and nutritional practices purely based on wild plants and their produce. This study was designed to promote such traditional knowledge of tribal and make it popularise among the other people. These systems of practices are indigenous, safe and cheaper mode of treatment to the people.

\section{${ }^{*}$ Corresponding Author:}

Dr. G. S. Deora,

Associate Professor, Department of Botany,

Jai Narain Vyas University, Jodhpur-342005, INDIA.

E-mail: gsdbiotech04@yahoo.co.in
The tribal of the study area are facing an onslaught of various types of Mother-Child diseases, particularly in poverty-stricken tribal areas where not enough and easily available facilities exist for medical treatment. Illiteracy and ignorance are some of the factors responsible for death of women at delivery time, malnutrition of child and even death of the infant. The under-nourished womenfolk are more affected as they became easy victims of ailments connected with intestinal and reproductive organ.

Rajasthan is one of the second largest state and is located in the Northwestern part of India. Geographically, it lies between $23^{0} 3^{\prime}$ to $30^{0} 12^{\prime}$ longitudes and 69030' to $78^{0} 17^{\prime}$ latitudes. Southern part of Rajasthan comprises with Banswara Chittorgarh, Dungarpur, Pratapgarh, Rajsamand and Udaipur districts. It is also known as tribal belt of Rajasthan which is dominated by Bhil, Damor, Garasia, Kathodia and Meena tribes.

The tribal of the study area are facing an onslaught of various types of Mother-Child diseases, particularly in poverty-stricken tribal areas where not enough and easily available facilities exist for medical treatment. Illiteracy and ignorance are some of the factors responsible for death of women at delivery time, malnutrition of child and even death of the infant. The under-nourished womenfolk are more affected as they became easy victims of ailments connected with intestinal and reproductive organ. 
The study area is a treasure of traditional knowledge of local flora and fauna. Even today, these tribes are using their own health and nutritional practices which has important role in meeting out their health needs. The main occupations of the tribes of the area are agriculture, livestock rearing (especially goat rearing) and wage labour. Continuous drought and no other option of service, they face difficulty in managing the daily meals for themselves and their children. The children suffer from malnutrition due to lack of traditional knowledge. Mother-infant mortality rate is increasing very fast in this area. The modern medicine is extremely expensive and is available only for who are financially sound. Due to poverty tribal women and their children are far away from this system of medicine. The need is to create more awareness and promote such type of tested practices and scientifically validated through proposed study.

Keeping in mind suggestions of "Rio Earth Summit (1992) that indigenous (ethnic) people and other communities have a vital role in environment and sustainable management because of their knowledge about plants and traditional practices in the developing countries.

Ancient Indian and world literature in medicine suggest that primitive people used several types of medicinal plants for combating diseases. Plants like Rauwolfia serpentina, Papaver somniferum and Cinchona officinalis have long been used to treat disease of body and mind. Some knowledge of ancient Indian medicines and medicinal herbs has been handed down to generations and has survived among the ethnic communities of India (Bodding, 1925).

Ethnic people generally use the plants growing nearby areas to fulfill their needs. A significant contributions has been made by various workers in Rajasthan such as Singh (1999), Sabastine and Bhandari (1984), Jhoshi (1995), Katewa and Arora (1997), Singh and Pandey (1998), Katewa and Chaudhary (2004), Trivedi (2002), Jan et al (2005), Deora and Jhala (2002), Deara and Jhala(2016), Meena (2014), Jain (1981) but all these studies were mainly made together traditional knowledge about ethno-medicinal plants and document them but there was a lacuna about traditional health care and nutritional practices particularly for mother and child in this area and document them. Therefore to collect the information about the plants of tribal dominated areas of Rajasthan and to document was the main objective of this study.

\section{Materials and Methods}

The study area was selected tribal dominated blocks districts of Rajasthan such as Banswara, Chittorgarh, Dungarpur Pratapgarh and Udaipur. An inventory was made of women traditional health practitioners (Dais, Midwives) in the study area through consultation of local NGOs and well known traditional health practitioners or traditional folk healers (known as Gunis) in the area. The frequent meetings were organized in villages with active involvement of local women, health practitioners and elders, who are known as Dais or midwives and having expertise to provide traditional health care services to pregnant and lactating mother in the study area. The personal interviews and local group discussions were held with the above target groups for documentation of their traditional health and nutritional practices. The local resource persons were also involved for location of tribal villages, traditional practitioners, translation of local dialect, local name of plant, etc. The transect walk was also conducted to know the situation of village particularly socio-economic condition and available natural resources in the village. A visit to nearby forest area or dense vegetation was also organized by involving traditional folk healers to identify plant species which are being used by them. The selected plant specimen were collected from the field and further consulted with herbaria for botanical identification of plant species. Plants collected during the surveys were identified with help of published regional floras such as Bhandari (1984), Shetty and Singh (1993), Sharma (2002, a, b), and by comparing voucher specimens with identified herbarium collections in the herbarium.

\section{Results}

The traditional system of health care by herbal medicine is an ancient system of treatment which born with the evolution of human civilization. Once men realized the significance of "Wonder herb" they recorded them in mind, learned by initiation and transmitted orally or passed their knowledge either from generation to generation or through "Guru-Shishya Parampara". Thus from thousands of year indigenous community or tribal have developed their own health practices and discovered healing properties of plants which is called as 'Ethno-medicines".

During the study, group discussions, personal interviews were made with the target group i.e. traditional women health practitioners of the study area. It was observed that the women are very particular about the uses of plant and its parts as home remedies for their reproductive health care. It was observed that with increasing population, facing an onslaught of various types of diseases and infection among tribal women. Illiteracy, poverty and ignorance about personal sanitation are some of the factors causing disease among tribal women population. In the study areas not enough and easily available health care facilities and they have to depend upon the costly modern health care system which they can't afford. The Aravalli terrain of Rajasthan is crossing over tribal district Dungarpur which has abundance of varied number of wild 
plant species, some of which are being used as remedies for reproductive-child health care in the area.

In this chapter information gathered from tribal women traditional health practitioners and other associated rural persons in the study area. The different plant species are being described in following order of botanical name, family, local name, habit and disease formulation/details uses suggested by women as knowledge keepers.

\section{Abrus precatorius Linn}

\section{LEGUMINOSAE}

Local Name: Charmoli

Habit: Perennial, twining shrub.

Leaves are eaten in the morning and evening till cured - Sore throat.

At least one handful of leaves are crushed and kept in two cup of water for five to six minutes and then strained. One cup infusion is taken in the morning and evening for three days - Gonorrhoea.

\section{Achyranthes aspera Linn.}

\section{AMARANTHACEAE}

Local Name: Andhijara

Habit: Annual herb.

The ripe seeds are roasted on a pan and the seed cover winnowed off after pouncing them slightly then powder is made from these seeds. One pinch of powder is mixed with breast milk or water and given thrice a day for 3 days - Cough in infants.

The ripe seed cover is winnowed off after slightly pouncing the seeds. These cleaned seeds are then cooked. The morning meal is to consist of cooked seeds for 7 days. - Excessive eating habit.

Root is crushed to make powder. This powder is taken twice a day for 7 days - Urinary complaints.

\section{Actinopteris dichotoma Bedd. \\ POLYPODIACEAE}

Local Name: Morpankhi

Habit: Herb

Whole plant is crushed and grinds to prepare juice, then filtered. One or two drops dripped in ear for two to three days- Ear ache.

Ampelocissus arnotiana Planch

\section{VITACEAE}

Local Name: Khatta- limbu

Habit - Woody climber

Grind fresh roots and filter in one glass of water are use in Leucorrhoea.

\section{Asparagus racemosus Wild.}

\section{LILIACEAE}

Local Name: Shatavari

Habit - Woody climber

Mix one tea spoon full of dried roots powder and 2 tea spoon full of sugar in a glass of water and take this morning \& evening for 3 day for Lactation.
Bacopa monneri Linn. Penll.

\section{SCROPHULARIACEAE}

Local Name: Balm

Habit - Creeping herb

Juice of decoction is prepared from whole plant, mixes with sugar and stored. One teaspoonful is taken twice a day to treat- Mental debility, Asthma.

\section{Baliospernum montanum Muell.}

\section{EUPHORBIACEAE}

Local Name: Dantri

Habit: Under shrub.

Root decoction / Juice is prepared. One teaspoonful decoction is taken twice a day during indigestion problem after eating. Root juice is dripped in opposite car during tooth ache, once in day - Indigestion, Tooth-ache.

\section{Baubinia vablii W\&A.}

\section{LEGUMINOSAE}

Local Name: Joganbel

Habit: Woody evergreen climber

Young shoot is cut into small pieces. These pieces are eaten twice a day for five days - Bone fracture.

Boerhaavia diffusa Linn.

NYCTAGINACEAE

Local Name: Hatadi

Habit - Prostrate annual herb.

Fresh roots are coarsely ground. Two cups of this paste is used to make a decoction, which is strained and cooled. One cup of decoction is taken in the morning and evening - Joints, body and liver swellings.

Quarter cup of this plant + quarter cup of Indian corn hair. This mixture is put in a vessel with 6 cups of water and boiled. When $1 \frac{1 / 2}{2}$ cups decoction is left this is strained and cooled. Half cup decoction is taken thrice a day for two or three days - Painful menstruation.

\section{Blepharis sindica T. Anders}

ACANTHACEAE

Local Name: Bhangri

Habit: Prostrate herb

Root is cut into small pieces. These pieces are ground to prepare paste. The paste is taken with water twice a day till cured - Typhoid.

\section{Butea monosperma}

\section{PAPILIONACEAE}

Local Name: Khakhra

Habit: Tree

$100 \mathrm{gm}$. flowers and $500 \mathrm{gm}$. mishri grind and prepare 3 doses. Moisten one dose in the evening in earthen pot, filter with cloth in the morning and take for Leucorrhoea.

Caesalpinia bonduc (Linn.) Roxb.

LEGUMINOSAE

Local Name: Katkaranj 
Habit: Spiny luxgreen shrub.

Juice is squeezed from fresh washed leaves. One teaspoonful juice is taken every morning till cured Rheumatism, Intestinal worm.

Cassia auriculata Linn.

\section{LEGUMINOSAE}

Local Name: Anwal

Habit: Perennial Shrub.

Roots are ground to make powder. This powder is taken once a day in - Diarrhoea.

\section{Cassia tora Linn.}

\section{LEGUMINOSAE}

Local Name: Puwadio or Punwad

Habit: Annual herb.

Seeds powder mixed with butter/ milk is used externally to treat - Ringworm.

Boiled tender shoot is eaten till cured - Anaemia, Stomach disorder.

Celastrus paniculatus Wild.

\section{CELASTRACEAE}

Local Name: Malkangni

Habit: Climber

Two seeds are ground and mix with milk. Fresh preparatiaon is taken daily once in day Rheumatism, Impotency.

\section{Cayratia trifolia (L.) Domin.}

\section{VITACEAE}

Local Name: Chota Khata Limbu

Habit: Climber.

The root is washed and cuts into small pieces, slightly ground. Then it is boiled to prepare decoction. One teaspoonful decoction is taken daily - Menorrhagea, Diarrhoea.

Celosia argentia Linn.

\section{AMARANTHACEAE}

Local Name: Dholikukdi/ Sufed murga

Habit: Annual Herb

One fistful roots or one teaspoonful of seeds are pounced fine and a cup of cold infusion is prepared. One cup infusion is taken in the morning and evening till cured - Urinary complaints.

\section{Cissampleos pariera Linn.}

\section{MENISPERMACEAE}

Local Name: Phangwel Habit: Perennial climber Fresh crushed roots are eaten with water daily to cure - Diarrhea.

Fresh washed leaves eaten to cure - Leucorrhoea.

Cocculus birsutus (Linn.) Diels.

\section{MENISPERMACEAE}

Local Name: Thikari/Bebalu/Jamti-ki-bel

Habit: Perennial climber.

The Paste is prepared by grinding are plant. Then this paste is put into one cup of water for short time. It is not to be strained. One cup of this mixture is taken in the morning and evening daily for 5 days - Jaundice.

Corallocarpus epigaeus Benth.ex. Hook.F.

\section{CUCURBITACEAE}

Local Name: Micrchio Kand Habit: Annual herb. Fresh root is cut into small pieces and mix with Jaggery. One piece is eaten daily twice a day Pneumonia.

Costus specious (Kaen.) Sm.

\section{ZINGIBERACEAE}

Local Name: Vailakadi

Habit: Annual Herb

The fresh prepared paste is applied on the joint for two to three days - Joint pain.

\section{Corchorus tridens Linn.}

\section{TILIACEAE}

Local Name: Razang

Habit: Annual herb.

Seeds are grounded to make powder. A pinch of powder is swallowed with water once a dayStomach- ache, Malaria.

Seeds powder is prepared as above. A pinch of powder is taken every 5 minute till the person vomits- Snake bite.

\section{Curculigo orchioides Gaerth.}

\section{AMARYLLIDACEAE}

Local Name: Kalimusli Habit: Annual herb. Fresh crushed root is eaten twice a day - Diarrhea. Cuscuta reflexa Roxb. CONVOLVULACEAE

Local Name: Amerbel or Akashvel

Habit: Complete parasite climber

The climber is cut into small pieces then boiled with water in a vessel. The infant is bathed with this water twice a day for 4 days- Fever in infants.

Decoction is prepared as above. One teaspoon decoction is taken daily and bath with this water Jaundice.

Climber is dried and ground to make powder. One teaspoonful powder is given to the patient twice a day - Anemia.

The patient should be bathed with this water twice a day - Fever or loss of appetite after delivery.

Cymbopagon martinii (Roxb.) Wats.

\section{POACEAE}

Local Name: Rohis or Rosha Grass

Habit: Grass

Leaves are boiled with water to get decoction. One teaspoonful decoction is taken once a day Jaundice.

Roots decoction is prepared as above. One cup decoction is taken daily for 3 days - Urinary complaints.

\section{Cyperus rotundus Linn.}

\section{CYPERACEAE}

Local Name: Jaldunglo

Habit: Perennial grass 
Leaves are boiled with water to get decoction. One tea spoon full decoction is taken once a day Jaundice.

Roots decoction is prepared as above. One cup decoction is taken daily for 3 days - Urinary complaints.

The paste of tuberous root is prepared and applied in the morning and evening- Black patches on skin, Abscess, Boils.

Delonix elata Gamble.

\section{LEGUMINOSAE}

Local Name: Handedo Habit: Tree

Stem bark is cut into small pieces and crushed. A decoction is prepared of crushed stem. 1/2 cup of decoction is taken in the morning - Dysentery and Leucorrhoea.

At least two handful leaves and a fistful of goat's dung are mixed and crushed. The mixture is tied on the abdomen every evening for three daysPneumonia in infants.

Dioscorea bulbifera Linn.

\section{DIOSCOREACEAE}

Local Name: Jatashankari Habit: Herbaceous climber

Sun dried tuberous root is ground to get powder. One teaspoonful powder is taken with water in the every morning - Jaundice, Pneumonia.

Diplocyclos palmatus (L.) Jaffery.

\section{CUCURBITACEAE}

Local Name: Ankhphutania or Shivlingi

Habit: Annual climber.

Needed amount of seeds are crushed to make a fine powder. From the 4th day of menstrual period the seeds powder is taken in the morning as mentioned below Sterility due to blocked tubes in women: $1^{\text {st }}$ day - 5 seeds, $2^{\text {nd }}$ day -7 seeds, $3^{\text {rd }}$ day -9 seed, $4^{\text {th }}$ day - Onwards 11 seeds every morning till the $15^{\text {th }}$ day. Fruit powder is also used in Diarrhoea.

Echinops echinatus Roxb.

\section{ASTERACEAE}

Local Name: Untkanta or Untkatara

Habit: Perennial under shrub

Roots are also tied on the head for Easy Delivery.

Elytraria acaulis (Lf.) Lind.

\section{ACANTHACEAE}

Local Name: Homulee Habit: Herb

Roots are cut into small pieces. These pieces are ground with water to obtain juice. Two teaspoonful juice is taken in the morning and evening for 7 days - Leucorrhoea.

Root juice is obtained and mix turmeric powder. One teaspoonful mixture is given to the patient daily till cured - Pneumonia.

Enicostemma byssopifolium Linn. (Wild)

GENTINACEAE

Local Name: Naami, Naval
Habit: Herb

Whole plant is crushed to get juice. Half cup of juice is taken daily for two days - Leucorrhoea and Irregular menstruation.

\section{Eulophia campestris Wall.}

\section{ORCHIDACEAE}

Local Name: Kukadiyo Habit: Annual herb

Tuber is dried, powdered and mix with milk. One teaspoonful powder mix with milk and taken daily for 15 days - Impotency, Leucorrhoea.

\section{Euphorbia caducifolia Haines}

\section{EUPHORBIACEAE}

Local Name: Thor

Habit: Perennial thorny shrub

"Bhasma" is prepared from shoot. One teaspoonful "Bhasma" is taken daily for three days after menstruation as - Contraceptive.

10-12 drops of latex is spread on the "Papad" then it roasted. One "Papad" is eaten every day for five days - Diarrhea.

Ficus racemosa Linn.

\section{MORACEAE}

\section{Local Name: Gular}

Habit: Tree

A cut is made on the stem. A vessel is placed under the cut (in the morning this is collected. The latex will drip into the cup. This latex is mixed with jaggary. One teaspoonful of mixture is given in the morning for five days- Urinary complaints.

Mature fruit is cooked with rice. Fruit mixed rice is eaten once a day for three days- Excessive bleeding after delivery.

Leaves are crushed and trained with cloth to get juice. The juice is mixed with butter or milk. Two teaspoonful mixture is taken in the morning for five days - Jaundice.

\section{Helicteris isora Linn. STERCULIACEAE}

Local Name: Atedi, Marod- Phali

Habit: Shrub

One pod is crushed and mix with breast milk. The infusion is given to infants - Indigestion in infants.

Roots are crushed and mix with milk. One cup of this mixture is taken daily for three daysLeucorrhoea.

Hemidesmus indicus R.Br.

ASCLEPIADACEAE

Local Name: Kabri dudhi Habit - Prostate climber One handful of washed roots are crushed and put in two cups of water for 15 minutes and then strained. One cup of infusion is taken in the morning and evening for 10 days - Gonorrhoea.

Holarrhena antidysenterica Wall.

APOCYNACEAE

Local Name: Kaduwa Habit: Tree 
Dry bark is powdered. One pinch of powder is taken with tea once in a day till cured - Diarrhea, Dysentery.

Seeds are removed from mature and ripe pods. Then roasted on a pad ground to the powder. One pinch of powder is to be taken with jaggery early morning for seven days - Intestinal worms.

\section{Jatropha curcas Linn.}

\section{EUPHORBIACEAE}

Local Name: Ratanjot Habit: Small tree

Dry seeds are crushed well to make powder. One fourth teaspoonful of powder is taken - Stomatitis, Indigestion.

Leea indica (Burm. F.) Merrill.

\section{VITACEAE}

Local Name: Chotihathani Habit: Herbs

Roots are cut into small pieces. One or two handful roots are ground and strained to get juice. One teaspoonful juice is taken daily for three daysDiarrhoea, Dysentery.

Leea macrophylla Roxb. Ex Hornem.

\section{VITACEAE}

Local Name: Motihathani

Habit: Annual under shrub

Roots is cut into small pieces and boiled into water. Then water is separated out. One-cup water is taken in the morning for seven days- Impotency.

Leptadenia reliculata (Retz.) Wt. \& Arn.

\section{ASCLEPIADACEAE}

Local Name: Bhatta Dodi Habit: Twining shrub Washed and dried roots are ground to make powder. One teaspoonful powder is taken with water for five days - Leucorrhea Stomach-ache.

Fresh leaves and fruits are collected. Fresh leaves and fruits are eaten daily for a week - Breast milk complaints.

Melia azedarach Linn.

\section{MELIACEAE}

Local Name: Bakain Nimbado

Habit: Tree

The fresh leaves are ground with young child's urine and warmed. The paste is bandaged on the chest at bedtime for two-thrice days- Chest pain.

Two handful leaves are steamed. Steam leaves are tied on the abdomen and chest twice a day- Baby's bronchitis.

Mytragyna parvifolia Korth.

\section{RUBIACEAE}

Local Name: Kamri

Habit: Tree

Stem is cut into small pieces and ground into fine powder. One teaspoonful powder is taken in the morning until cured-Pneumonia.

Ocimum gratissimum Linn. LABIATAE

Local Name: Damano, Jangli- tulsi.

Habit: Herb.
The seeds are ground to make a fine powder and put in half a cup of water to prepare cold infusion. Half cup infusion is taken in the morning and evening-Burning urination or White discharges. Seeds powder is prepared as above. One teaspoonful powder or seeds is taken in the morning and evening for four days - Urinary complaints.

\section{Ocimum americanum Linn.}

\section{LABIATAE}

Local Name: Bhutbhangro

Habit: Herb.

Seeds are ground to make mix with mishri (Sugar crystals). Two teaspoonful mixture is taken with milk in the morning for four days - Urinary complaints, Leucorrhoea.

\section{Opuntia dillenii \\ CACTACEAE}

Local Name: Naagphani

Habit: Herb

Cut one phylloclade piece into two length-wise. Sprinkle common salt on spiny surface, warm on fire and tie on tumor for 3-4 days. in oozing tumor Internal Tumor.

\section{Phyllanthus niruri Linn.}

\section{EUPHORBIACEAE}

Local Name: Bhuiamla

Habit: Herb

Root powder or juice of the whole plant is prepared. Half teaspoonful powder or half cup of juice is taken on an empty stomach in the morning for five days - Jaundice.

Juice is prepared as above. One cup of juice is taken in the morning on empty stomach- Swelling in abdomen.

\section{Petrocarpus amarsuplum Roxb.}

\section{LEGUMINOSAE}

Local Name: Biyo

Habit: Tree

Bark is crushed to prepare powder. Two teaspoonful powder is taken in the morning for tree days - Excessive menstruation, Diarrhoea, Dysentery.

\section{Pueraria tuberasa Dc.}

\section{LEGUMINOSAE}

Local Name: Modikand, Godvelo

Habit: Climbing Shrub

Roots are cut into small pieces then grind to a fine powder. Two teaspoonful powder is taken with milk daily for 15 days - Impotency.

\section{Rhynchosia minima Dc. \\ LEGUMINOSAE}

Local Name: Kalthivelo

Habit: Herb

Root is ground to make powder. One teaspoonful powder is taken with water in the morning, 
sometimes fresh roots are chewed - Urinary complaints, Dysentery, Diarrhea.

\section{Sarcostemma acidum (Roxb.) Voiget}

\section{ASCLEPIADACEAE}

Local Name: Sambharvel

Habit: Scandent climber

Fresh shoot is crushed to prepared juice. Half cup fresh juice is taken once a day for three days Burning sensation of body.

\section{Tribulus terrestris Linn.}

\section{ZYGOPHYLLACEAE}

Local Name: Gokhru Kanti

Habit: Prostate annual Herb

The fruit powdered is given to cure - Urinary complaints, Leucorrhoea.

\section{Vitex negundo Linn.}

\section{VERBENACEAE}

Local Name: Nirgundi, Negad

Habit: Perennial Shrub

One cup of roots are crushed and put into four cup of water. On boiling, the water is reduced to one cup, cooled and taken. One cup decoction is taken thrice a day for three day - Pain in arms and legs.

\section{Xanthium strumarium Linn.}

\section{ASTERACEAE}

Local Name: Andyo

Habit: Annual herb

The whole plant is crushed to a fine paste, mix with turmeric powder. The paste is applied in the morning and evening - Breast abscess.

Zizyphus numularia W. and A.

\section{RHAMNACEAE}

Local Name: Chanber

\section{Habit: Shrub}

Roots are crushed to prepare paste. The paste is taken with water for five days-Irregular menstruation, Menorrhea.

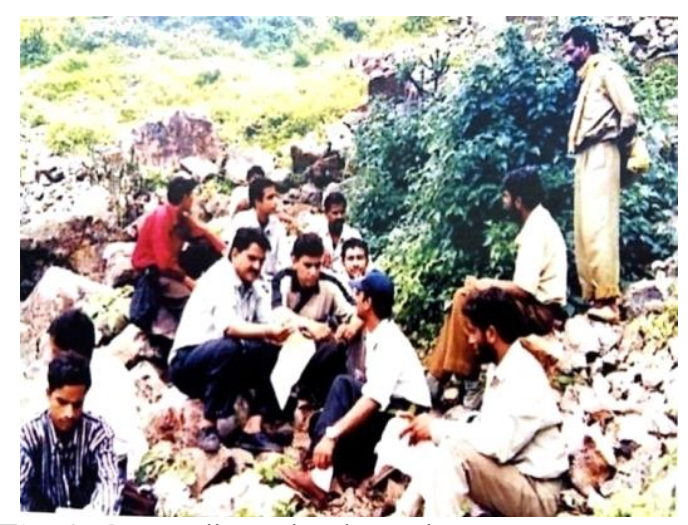

Fig. 1. Group discussion by author

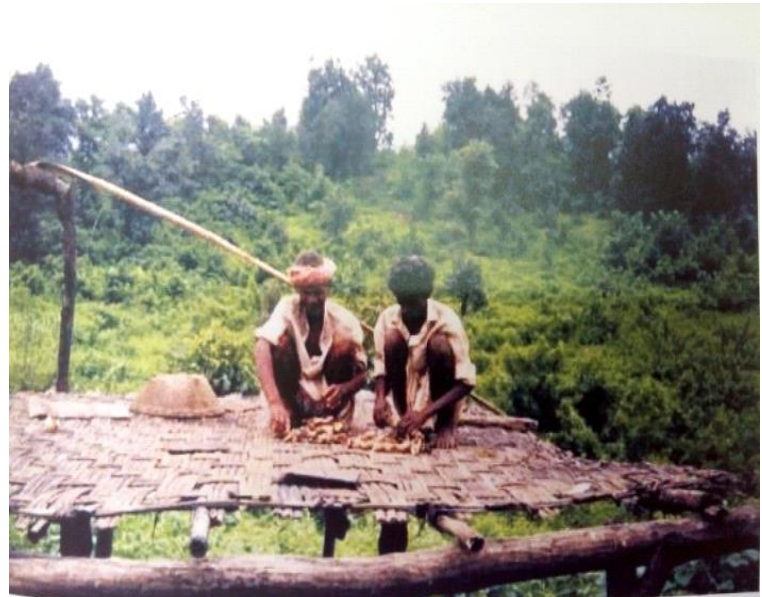

Fig. 2. Traditional method of drying herbal medicine

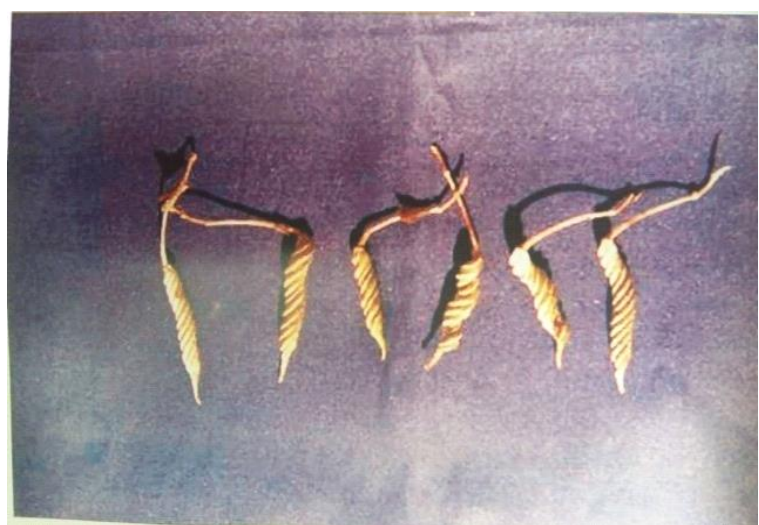

Fig. 3. Fruits of Helicteris isora (Marod phalli)

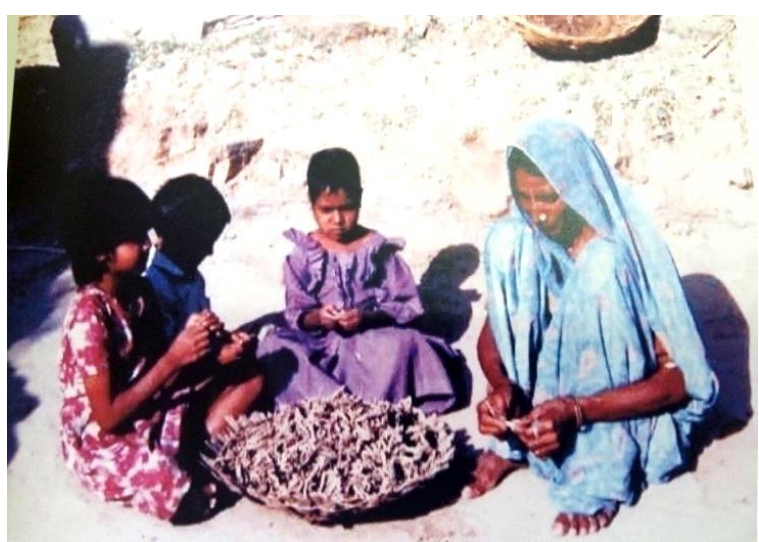

Fig. 4. Childrens with mother engaged to separate herbal medicine

\section{Discussion}

India is rich in the history of medicinal plants and its 75 per cent of folk population is still using herbal preparations in form of powder, extracts and decoction because these are easily available in the nature and the natives having strong faith on traditional knowledge (Dixit, 1974). Jai (1991, 1995) stated that the traditional knowledge of tribals or ethnic people plays an important role in quick and proper identification of natural resources and discusses the scope of ethnobotany. From 1977 and 
onwards the World health organization (WHO) gave formal recognization to traditional medicine, there were several valuable publications on its belief. The role of WHO on the origination, promotion and development of researches on traditional medicine with mutual cooperation among the developing countries was emphasized Bannerman, 1980; Baasher, 1982).

Katewa and Galav (2005) reported 48 species of dicotylednous and 2 species of monocotyledonous from Shekhawati region of Rajasthan and discussed their traditional medicinal importance. Rana et al., (2014) identified and documented 48 plant species belonging 35 genera and 22 families employed ethno-medicinally by the rural people of Ghatol, Banswara district Rajasthan.

Deora and Jhala (2016) documented 36 herbal formulations of 59 plant species belonging to 40 families to cure 16 common diseases suggested by 32 traditional health practitioners of tribal dominated areas of Udaipur, Dungarpur, Banswara and part of Sirohi and Chittorgarh of Rajasthan further Deora and Rathore (2017) documented herbal formulations of 19 plant species belonging to 14 families from different parts of southern Rajasthan which were used by the ethnic medicine men for the treatment of various types of animal diseases.

On the basis of above discussion it can be said that all the studies were focused mainly on tribal health but present study was focused on mother- child health care and ameliorate the health status of mother and child after the birth and up to five years of age of child.

\section{Conclusion}

The present study was carried out in the tribal dominated areas of Rajasthan to identify and documents herbal plants and their produce used by the tribals to ameliorate the health status of mother and child after birth. Further it is concluded that in the present work 55 plant species belonging to 52 genera and 35 families have been collected, identified and documented which were used to treat various types of mother-child ailments after birth and upto five years age of child.

\section{Acknowledgement}

Authors are thankful to all the tribals of the study area who provided oral information about the local name of plants and their uses for traditional animal health care and to cure different types of diseases. Authors are also thankful to UGC for providing financial assistance through CAS programe in the Department of Botany Jai Narain Vyas University Jodhpur (Rajasthan).

\section{References}

1. Baasher T. Promotion and development of research in traditional medicine. WHO Journal of Ethnopharmacology, 1982.2:75-79.

2. Bannerman RH. Organisation and cooperation of the development of studies on plant used in traditional medicine, some guidelines for research and studies. Journal of Ethnopharma, 1980, Vol.2 (2), 189-192.

3. Bhandari MM. Flora of Indian desert, Scientific Publishers, Jodhpur, Rajasthan, 1990.

4. Bodding OP. Study in Santhal medicine and connected folklore I and II, Meorir of Asiatic Society of Bengal 1925, Vol.10 (2), 133-426.

5. Deora GS and Rathore MS. Ethno-veterinary medicine (EVM) and traditional practices in animal health care system (AHCs) in the southern part of Rajasthan, India, International Journal of Ayurvedic and Herbal Medicine 2017,7(4), 2746-2751.

6. Deora GS and Jhala GP Singh. Ethno-medico botanical diversity of Kotra region Udaipur, Rajasthan,In: Dadhich LK (Ed.) Biodiversity: Strategies for conservation of plants, APH Publishing house corporation, New Delhi 2002, PP, 317-329.

7. Deora GS and Jhala GP Singh. Studies on ethnomedicine and role of traditional health practitioners (THPs) in primary health care systems (PHCs) in the tribal dominated areas of Rajasthan, India. International Journal of Pharmacognosy, (2016), 3(8), 359-370.

8. Dixit RD. Ferns: A much neglected group of medicinal plants. Journal of Research in Indian Medicinal plants, 1974, 9, 74-90.

9. Jain A Katewa SS Galan PK and Sharma P. Medicinal plant diversity of Sitamata Wild life sanctuary Rajasthan, India, Journal of Pharmacognosy, 2005, 102,143-157.

10. Jain SK. Dictionary of Indian folk medicine and ethnobotany. Deep Publications Paschim Vihar Dehli, 1991.

11. Jhoshi P,.Ethnobotany of primitive tribes of Rajasthan. Printwell, Jaipur, India (1995), 1-313.

12. Katewa SS and Arora A, Some plants in folk medicine of Udaipur district, Rajasthan, Ethnobotany, 1997, 9:48-51.

13. Katewa SS Chaudhary BL and Jain A. Folk herbal medicines from tribal area of Rajasthan, India, Journal of ethnopharmacology, 2004, 92(1), 41-46.

14. Meena KL and Yadav BL. Some traditional ethnomedicinal plants of southern Rajasthan, India. Indian Journal of traditional knowledge, 2010, 9(3), 471-474. 
15. Meena KL. Some traditional ethno-veterinary plants of district Pratapgarh, Rajasthan, India, American Journal of Ethno-medicine, 2014, 1(6), 393-401.

16. Rana Shafkat Sharma SK and Paliwal PP. A note on ethno-medicine properties of some plants used by the tribal and rural community in Ghatol area of district Banswara of South Rajasthan, India. Research Journal of medicinal plants, 2014, 8(6), 246-257.

17. Sabastine MK and Bhandari MM. Medico-ethnobotany of Mount Abu, Rajasthan, India. Journal of Pharmacology, 1984, 12:223-230.

18. Sharma NK. The flora of Rajasthan, Aavishkar publishers, Jaipur, 2002. PP 1-280.

19. Sharma NK. Ethno-medico religious plants of hadoti plateau (S.E. Rajasthan), A Preliminary survey, In: Trivedi PC (Ed.) Ethnobotany, Aavishkar publishers, Jaipur, India, 2002.
20. Shetty BV and Singh V. Flora of Rajasthan, Botanical survey of India, Calcutta, 1993.

21. Singh V and Pandey RP, Ethnobotany of Rajasthan, India, Scientific Publishers, Jodhpur, Rajasthan, 1998.

22. Singh G. A contribution in ethnomedicine of Alwar district of Rajasthan. Ethnobotany, 1999, 11:97-99.

23. Trivedi PC. Ethno-medicinal plants of Rajasthan state, India, In: Trivedi PC (Ed.) Ethnobotany, Aavishkar publishers, Jaipur, India, 2002, PP. 412439.

\section{Cite this article as:}

G.S. Deora and M.S Rathore. Traditional Health Care (THC) and nutritional practices in Mother Child Health Care Systems (MCHCS) in the tribal dominated areas of Rajasthan, India.Annals of Plant Sciences 7.2 (2018) pp. 2047-2055.

do $\mathrm{http}: / /$ dx.doi.org/10.21746/aps.2018.7.2.11

\section{Source of support: UGC, CAS Conflict of interest: $\mathrm{Nil}$}

